\title{
Physical activity for health and wellbeing: the role of motives for participation
}

Health professionals have increasing concern about physical health and wellbeing, as life globally becomes more demanding and stressful, yet people are less active, due to mechanization and automation of work and leisure. Increasing the amount of physical activity (PA) people do is now recognized as a global health priority, but PA continues to decline in many countries. Research on motives for participating in PA shows they have a role in PA promotion. We review theory and research on motives for participation in PA. Then, we describe development and validation of the Physical Activity and Leisure Motivation Scale (PALMS), a 40-item measure that includes eight motives. We report on the international validation of PALMS, showing its robustness to variations in language and culture. We describe the development of a youth version, PALMS-Y, and a broader version that adds motives related to extreme sports. Next, we discuss PALMS research that has examined differences in primary motives based on gender, age, and type of PA, as well as factorial structure invariance. We then consider studies investigating the influence of psychological variables on the relationship between motives for participation in PA and the amount of PA individuals undertake, including self-efficacy, mindfulness, and passion. To aid in the consistent presentation of PA participation motives, we describe a form of motivational profiling for use in research and practice. Finally, we propose ways that motives for participation in PA can be used in interventions to increase PA participation, by matching individuals' primary motives to the type of PA associated with those motives in large PA samples, or using techniques, such as imagery, to enhance key motives. This should achieve the aim of enhancing health and psychological wellbeing around the world.

KEY WORDS

motives; physical activity; health; psychometric measure

ORGANIZATION - 1: Institute for Health and Sport, Victoria University, Melbourne, Australia · 2: DR Academy, Melbourne, Australia

AUthors' Contributions - A: Study design - B: Data collection - C: Statistical analysis - D: Data interpretation ·

E: Manuscript preparation · F: Literature search · G: Funds collection

CORRESPONDING AUTHOR - Prof. Tony Morris, Institute for Health and Sport, Victoria University, 300 Queen Str., Melbourne, VIC 3000, Australia, e-mail:Tony.Morris@vu.edu.au

to Cite this ARTICLE - Morris, T., \& Roychowdhury, D. (2020). Physical activity for health and wellbeing: the role

of motives for participation. Health Psychology Report, 8(4), 391-407. https://doi.org/10.5114/hpr.2020.100111

RECEIVED 15.07.2020 • REVIEWED 18.08.2020 • ACCEPTED 24.09.2020 • PUBLISHED 20.10.2020 


\section{BACKGROUND}

There is growing concern about the physical health and psychological wellbeing of adults and children in many countries around the world (World Health Organization [WHO], 2020a). A major source of concern is the patterns of declining participation in physical activity (PA) in the population. This is observable at work, where many physical tasks have been automated, in instrumental PA, such as transport, shopping, housework, and gardening, and during leisure time, in sport and outdoor activities (WHO, 2020b). Given that the opportunities to increase PA in work and instrumental activities are limited, the role of leisuretime sport and PA is gaining greater priority among governments and major health organizations, such as the WHO (WHO, 2020c). Because most leisure-time sport and PA is optional, individuals must decide to participate, and the evidence is that participation is declining globally (WHO, 2020b, c). For the purpose of this article, we considered exercise and sport to fall under the broad rubric of $\mathrm{PA}$, as defined by the WHO (2020b). A key factor that influences individuals' decision to participate in leisure-time sport and PA is motivation (Morris \& Rogers, 2004; Roychowdhury, 2020). Thus, it is important to understand what motivates individuals to participate in leisure-time $\mathrm{PA}$ and sport, and the factors that influence motives for participation in PA. One promising approach to understanding motives for participation in PA is through their quantitative measurement, using validated instruments (Frederick \& Ryan, 1993; Morris, Clayton, Power, \& Han, 1996a). This allows researchers and practitioners in health-related PA to understand the range of motives for participation (e.g., Kueh, Kuan, \& Morris, 2017; Molanorouzi, Khoo, \& Morris, 2014) and to determine the relationship of motives to intensity of participation (Abdullah, Kueh, Hanafi, Morris, \& Kuan, 2019; Molanorouzi, Khoo, \& Morris, 2015b). Further, by using validated measures of PA participation motives, researchers have the potential to identify ways to enhance influential motives, leading to increases in the intensity of individuals' involvement in leisure-time sport and PA (Morris, 2019; Roychowdhury, 2019). The purpose of this paper is to describe the development and structure of one measure of motives for participation in PA, the Physical Activity and Leisure Motivation Scale (PALMS), to report its use in increasing understanding of the relationship between motives and PA, and to propose ways in which understanding gleaned from the measurement of participation motives can be applied to increase individuals' participation in leisure-time PA for physical health and psychological wellbeing.

Researchers have provided increasing evidence of the influence of PA on health and wellbeing. This work includes many studies that have related noncommunicable, chronic diseases, associated with the highest levels of global morbidity and mortality, to physical inactivity. This includes coronary heart disease (Wardoku, Blair, Demmer, \& Prizment, 2019), diabetes (Silva et al., 2019), and certain forms of cancer (Friedenreich, Neilson, \& Lynch, 2010). Conditions that affect psychological wellbeing have also been linked to low levels of physical activity. Pre-eminent among these are the pervasive psychological problems of depression (Dinas, Koutedakis, \& Flouris, 2010) and anxiety (Stubbs et al., 2017). Notably, researchers have demonstrated that interventions that are designed to increase participation in PA can reduce the risk of individuals contracting these lifethreatening physical and mental conditions (Centers for Disease Control and Prevention [CDC], 2020). Alternatively, research has shown that participation in regular PA can ameliorate the impact of these chronic conditions in people already experiencing them (Anderson \& Durstine, 2019). Evidence that participation in PA can protect against and help to manage the most prevalent life-threatening, non-communicable health risks is of critical importance, yet monitoring of the patterns of participation in leisure-time PA indicates that this knowledge has not led to an increase in the prevalence or intensity of participation in PA. In fact, participation continues to decline worldwide (WHO, 2020b).

The WHO has monitored global levels of leisuretime PA for some time. Recent WHO data have indicated that levels of PA are not increasing (WHO, 2020a, b, c). Global estimates indicate that over the past 15 years, levels of insufficient activity have not improved (28.5\% in 2001, 27.5\% in 2016). Globally in $2016,23 \%$ of men and $32 \%$ of women aged $18+$ years were insufficiently physically active. In a recent study, Guthold, Stevens, Riley, and Bull (2018) reported that more than 1.4 billion adults are at risk of disease from not doing enough PA and that no improvement in global levels of PA has been recorded since 2001. Although local, state, and national governments, as well as major health organizations, have developed programs that aim to increase sport and PA participation, the evidence suggests that these have not reversed the trend of declining participation in leisure-time PA (Lewis, Napolitano, Buman, Williams, \& Nigg, 2016). The conclusion is that alternative strategies appear to be necessary to reverse the declining trend in participation in leisure-time PA. One approach that has potential is to examine the relationship between motivation and PA participation. More specifically, determining whether and understanding how motives for participation in PA influence actual levels of participation could lead to the development of approaches to promote PA participation in the population (Morris, 2019; Roychowdhury, 2019).

Based on the broader conception of motivation, researchers have examined the reasons why people participate in sport and PA. In perhaps the first 
substantive work of this kind, Gill, Gross, and Huddleston (1983) developed the Participation Motivation Questionnaire (PMQ) from qualitative research on youth sports. In an exploratory factor analysis (EFA) of PMQ items generated from interview themes, Gill et al. (1983) identified eight motives, namely achievement, team (affiliation/social), fitness, energy release, to be with others, skill, friends, and fun. Researchers applied the PMQ in studies of youth and adults participating in sport at various levels, as well as in general leisure-time PA (Brodkin \& Weiss, 1990; Buonamano, Cei, \& Mussino, 1995; Gould, Feltz, \& Weiss, 1985; Kirkby, Kolt, \& Liu, 1999; Klint \& Weiss, 1987; Kolt et al., 1999; Longhurst \& Spink, 1987; Morris \& Han, 1991; Morris, Power, \& Pappalardo, 1993; Sutherland \& Morris, 1997; Weinberg et al., 2000). A problem with research examining the PMQ is that the questionnaire was developed using an empirical, atheoretical approach. Gill et al. (1983) generated PMQ items from the qualitative study and the motives were derived from an EFA. When other researchers examined the PMQ, they derived a variety of motives varying from as few as four (Longhurst \& Spink, 1987) to as many as 11 motives (Morris \& Han, 1991). Morris, Clayton, Power, and Han (1995) added items, based on feedback from participants in their earlier studies. Thus, the research literature on the PMQ does not present a stable measure with a frequently replicated set of motives.

An alternative approach is exemplified by the development of the Motivation for Physical Activity Measure (MPAM; Frederick \& Ryan, 1993). Frederick and Ryan developed the motives in MPAM from Deci and Ryan's (1985) self-determination theory (SDT) in the context of PA for health and fitness. In the original MPAM, there were just three motives, namely interest/enjoyment, competence motivation, and bodyrelated motivation, which addressed the competence and autonomy needs that Deci and Ryan proposed as the sources of motivation. In a revision of the measure, Ryan, Frederick, Lepes, Rubio, and Sheldon (1997) added a social motive to address the relatedness need proposed in SDT. Ryan et al. (1997) also separated health into two motives that they termed fitness and appearance. The resulting Motivation for Physical Activity Measure-Revised (MPAM-R; Ryan et al., 1997) thus consisted of five motives. The MPAM-R still appears to lack a number of key motives that have been identified in other scales, based on empirical studies (e.g., Morris \& Rogers, 2004).

A number of other questionnaires have also been developed to measure participation motivation in sport and exercise contexts. These include the 28item Sport Motivation Scale (SMS; Fortier, Vallerand, Brière, \& Provencher, 1995), the 44-item Exercise Motivation Inventory (EMI; Markland \& Hardy, 1993), the 69-item EMI-2 (Markland \& Ingledew, 1997), and the 32-item Exercise Motivation Scale (EMS; Li, 1999).
Fortier et al. (1995) developed the SMS to examine the levels of self-regulation that Deci and Ryan (1985) proposed in organismic integration theory (OIT), a sub-theory of SDT. Thus, the SMS does not identify different motives. The EMI, EMI-2, and EMS all focus specifically on exercise, so they are not broad enough to cover all leisure-time PA.

To summarize, measures of motives for participation in sport and PA reflect variations in the number of motives that they include. A number of measures have emerged from empirical studies, so they are not underpinned by theoretical frameworks, whereas others have been developed on the basis of theories, so motives commonly present in empirically derived scales do not appear in the theoretically generated measures. Most measures of motives for participation in PA were developed in specific contexts and validated with samples from those contexts, so their justifiable application might be limited to those contexts, such as exercise, e.g., EMI, MPAM-R, or youth sport, e.g., PMQ. Ideally, measures should be developed that can be applied to sport and PA generally, that address the range of motives that are reflected across validated questionnaires and that are generated on the basis of empirical evidence, yet reflect theoretical underpinnings. Such measures should have the potential to enhance understanding of how motives for participation in PA can be applied to promote levels of involvement in sport and PA globally. It is within this context that the Physical Activity and Leisure Motivation Scale (PALMS) has been developed.

\section{DEVELOPMENT OF THE PHYSICAL ACTIVITY AND LEISURE MOTIVATION SCALE (PALMS)}

Development of the PALMS involved a number of stages. In the first of these steps, we conducted a qualitative study in which we asked recreational exercisers about what they considered to be success when they participated in PA (Rogers, Morris, \& Moore, 2008). We considered recreational exercisers to be individuals who participated in exercise that was not performed under a formal, rule-governed framework, such as running, but not in organized, competitive races, or doing aerobics, but not in team tournaments. This was intended to explore the achievement goals that exercisers espoused. We predicted that exercisers might have goals beyond the task and ego goals found in competitive sport (Duda, 1988). However, we were surprised to find that seven themes emerged that corresponded closely with motives for participation in PA. We decided to use the qualitative results as the basis to develop a questionnaire to measure participation motives. This questionnaire is the 73-item Recreational Exercise Motivation Measure (REMM). We validated the REMM in a study with a sample of
Role of motives for participation in physical activity 
Tony Morris,

Dev

Roychowdhury
750 recreational exercisers and a parallel study with a sample of 250 recreational level sport performers (Rogers \& Morris, 2003). We considered recreational sports performers to be individuals who participated in sport that was not performed under a formal, rule-governed framework, such as those who played basketball, but not in a formal league, or those who played tennis, but not in organized competitions. An EFA for each sample produced equivalent results, identifying eight factors that corresponded to motives for participation in PA. The health theme from the earlier qualitative study divided into two motives, which we identified as physical condition or health and appearance. The factors were not orthogonal, indicating that the motives grouped into higher-order factors, so we conducted a second-order factor analysis. This produced three second-order factors. Examining the motives that formed each of the second-order factors, we identified them as intrinsic motivation, extrinsic body-mind motivation, and extrinsic social motivation as shown in Figure 1.

REMM is a valid and reliable (the coefficient $\alpha$ for the total scale was found to be .94 in the recreational exercise sample and .92 in the recreational sport sample) measure of motives for participation in PA. However, at 73 items in length it is too long for use in research that involves multiple repeated tests of motives in the same sample over a period of time, such as when the participation motives measure is used to monitor changes in motives across a number of occasions due to interventions. Participants could experience boredom or fatigue that would affect their responses to later items in the REMM. Effects of the length of the REMM are likely to be even more problematic in applied work. In addition, results could be affected by variations in the number of items that measure each motive. In the REMM, the number of items varies from a minimum of eight items for the physical condition motive to a maximum of 13 items for the competition/ego motive. To create a more manageable scale, we used item analysis procedures to select the five strongest items for each motive (Morris \& Rogers, 2004). This produced a 40-item measure consisting of five items for each of eight motives. We called this measure the Physical Activity and Leisure Motivation Scale (PALMS) to reflect the scale of the changes that we had made. In light of the extent of change from the REMM to the PALMS, a reduction from 73 items to 40 items representing close to a $50 \%$ reduction in the number of items, we considered that it was appropriate to validate the PALMS.

We conducted a preliminary validation in Australia with a sample of 202 participants from five diverse types of PA (Roychowdhury, 2012, 2018a). The activities were tennis $(n=30)$, representing a racquet sport, Australian Rules Football or AFL $(n=42)$, representing a team ball sport, gym-based aerobics $(n=44)$, representing an exercise activity, taekwondo $(n=36)$, representing martial arts, and yoga $(n=36)$, representing a non-competitive physical activity. For

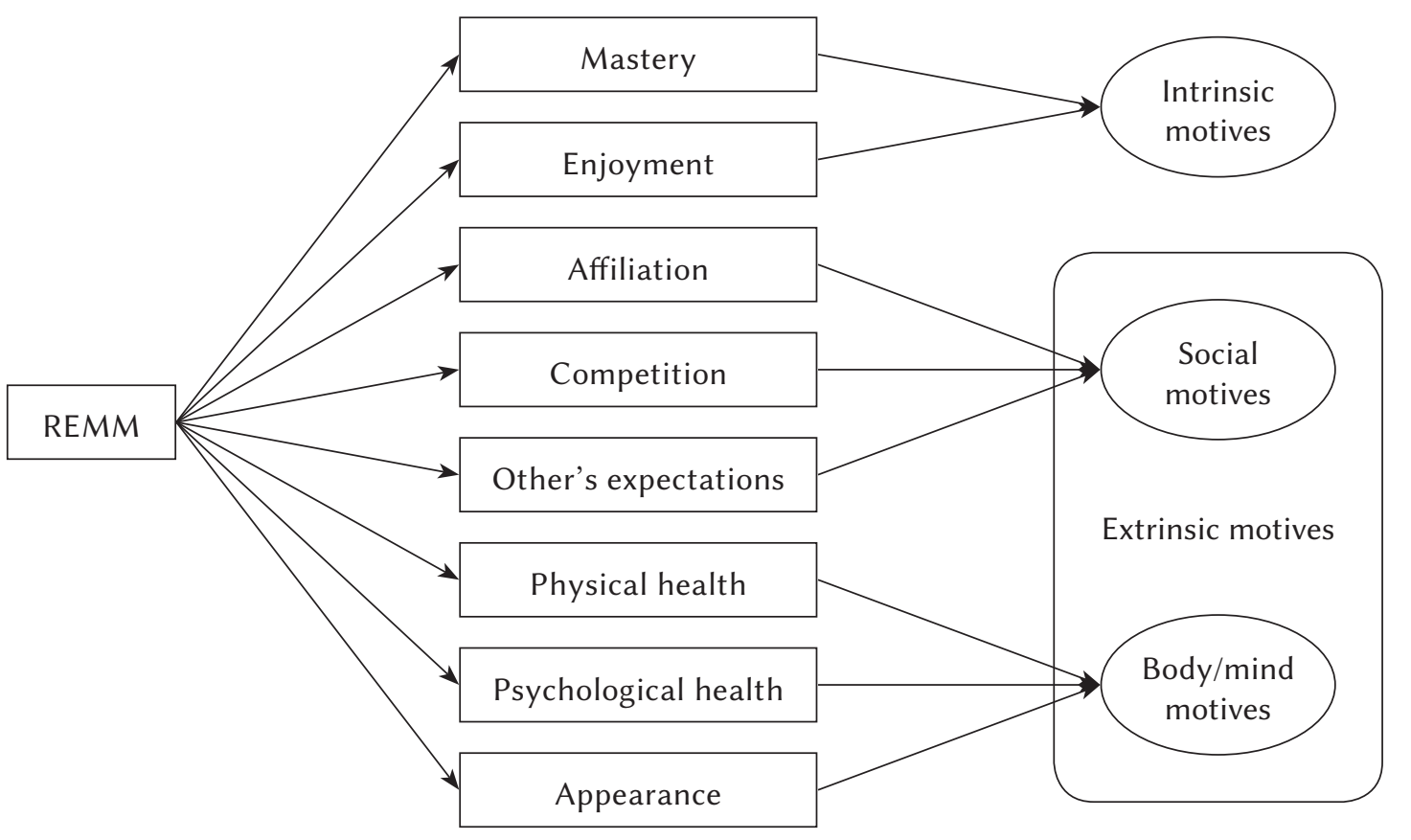

Note. From "Examining reasons for participation in sport and exercise using the Physical Activity and Leisure Motivation Scale (PALMS)" by D. Roychowdhury, 2012, Doctoral dissertation, Victoria University, Melbourne, Australia (http://vuir.vu.edu.au/19943/). Copyright D. Roychowdhury.

Figure 1. Second-order factor analysis of the eight motives of REMM. 
the purposes of validation, analyses were conducted with the whole sample. Internal consistency for the eight motive subscales was measured using Cronbach's $\alpha$ coefficient. Values of $\alpha$ were all acceptable, ranging from $\alpha=.80$ for the others' expectations motive to $\alpha=.99$ for the affiliation motive. We tested the 8 -factor structure of the PALMS using confirmatory factor analysis (CFA). The data produced a good fit to the 8-factor model, with $\mathrm{CMIN} / \mathrm{DF}=2.22, \mathrm{NFI}=0.95$, $\mathrm{CFI}=0.96$, RMSEA $=0.08$. We also examined criterion validity of the PALMS by correlating the eight motives in the PALMS with the corresponding eight motives in REMM. This also produced results supportive of the validity of the PALMS.

A primary reason we chose five activities, each of which represented a different type of PA, was to compare the results with findings from an earlier study in which we examined differences in motives for various types of PA, using the PMQ to measure motives (Morris et al., 1996a). In a large sample of 2,601 participants from 14 different sports and non-competitive types of PA, we compared racquet sports, including tennis, table tennis, and badminton, team ball sports, including hockey and AFL, individual body movement sports, including gymnastics and swimming, exercise activities, including aerobics and weight training, and martial arts, including judo, taekwondo, and tai chi. To test for differences in motives for participation between the five types of activity, we used discriminant function analysis (DFA) to differentiate each type of activity from the rest of the sample in turn. We found that racquet games participants scored higher on competition-ego than the rest of the sample. This suggests that individuals who are high on competition/ego chose racquet sports because racquet sports provide the clearest opportunity to demonstrate higher ability than others by defeating them in one-to-one competition. Team ball sports participants were discriminated from the rest of the sample by higher scores on the affiliation motive. This indicates that a pre-eminent reason why individuals chose team sports was to interact with others while playing sports. Not surprisingly, the discriminating motive for exercisers was physical condition. More than the rest of the sample, exercisers were motivated by the perceived health benefits of doing aerobics or weight training. Martial arts participants were discriminated from the rest of the sample by a strong motive to develop their skills and achieve mastery in their PA. This reflects the non-competitive nature of the martial arts we examined at the level of participation of most individuals in the study, as well as the importance of learning skills that were relatively new to many of these individuals. There was no discriminating motive for individual body movement participants.

In the study conducted by Roychowdhury (2012) 15 years later, using the PALMS, as opposed to the PMQ, results for sports and non-competitive activi- ties representing four out of the five types of PA in the earlier study were encouragingly similar to the earlier results. Competition/ego was prominent for racquet sports, affiliation was the pre-eminent motive for AFL players, physical condition was the most important motive for exercisers, and mastery was the primary motive for martial arts and yoga. Acknowledging that this was a preliminary study, given the limited sample size and the restriction to one activity of each type, the equivalence of results for the large sample 1996 study, using the PMQ, and the smaller 2012 study, using the PALMS, suggests that there might be consistent patterns of primary motives in categories of PA that share major characteristics, such as one-to-one competition, being part of a team, or improving health. This has implications for the use of motives to direct individuals to the type of activity that could satisfy their primary motives. Continued satisfaction of primary motives could lead individuals to participate at a greater intensity and continue participating for longer.

\section{INTERNATIONAL VALIDATION OF THE PALMS}

Since the first validation study done by Roychowdhury (2012), the PALMS has been validated in a number of countries around the world. For instance, Zach, Bar-Eli, Morris, and Rogers (2012) administered the PALMS to 678 regular exercisers (ages ranging from 9 to 89 years) in Hebrew in Israel and found that it demonstrated strong psychometric properties with reliability alphas ranging from .63 to .96. An EFA yielded nine factors: competition/ego, appearance, family and friends' expectations, health professionals' and employers' expectations, affiliation, physical condition, psychological condition, mastery, and enjoyment. Although the final factor structure that emerged from the analysis was very similar to that of the original PALMS, the factor labeled others' expectations was found to be split into two distinct factors: family and friends' expectations, and health professionals' and employers' expectations. Despite this, the structure produced in this study seemed to capture motives people have for participating in recreational exercise and sport that have previously not been covered by other questionnaires. The PALMS has also been validated in English in a Malaysian context, with 502 volunteer adult participants who represented a variety of PA categories, including individual sports, team sports, martial arts and exercise (Molanorouzi et al., 2014). Overall, the PALMS demonstrated strong internal consistency (Cronbach's $\alpha$ coefficient of .79) and test-retest reliability (values ranging between .78 and .94 for the eight motives over a 4-week period). A CFA revealed good fit indices for the 8 -factor model structure $(\mathrm{CMIN} / \mathrm{DF}=2.82$,
Role of motives for participation in physical activity 
$\mathrm{NFI}=0.90, \mathrm{CFI}=0.91, \mathrm{RMSEA}=0.06)$. The PALMS has also been administered in a Brazilian context, where it demonstrated strong internal consistency (Cronbach's $\alpha$ coefficient of .88) and factor structure (Frainer, 2017). Overall, these studies indicate that the PALMS not only demonstrated solid factor structure, reliability, and validity, but also showed its applicability to different cultural contexts.

Additionally, the PALMS has been translated into other languages. Zarei et al. (2016) examined the reliability, validity, and factorial structure of the Farsi version of the PALMS in a sample from the Iranian population. The forward translation of the PALMS from English to Farsi was done by two different independent bilingual translators whose first language was Farsi. Whereas one of the translators, who was a psychologist experienced in translating psychological questionnaires, was aware of the purpose of PALMS translation, the other translator had no psychological background and was uninformed about the purpose of the study. Once these two translators discussed differences in translation and resolved inconsistencies, the back translation of the Farsi version to English was performed by one bilingual translator whose first language was English. A multidisciplinary expert committee was then set up that evaluated and reviewed the final Farsi translation and back translation into English. This committee reached a consensus on a pre-final version of the Farsi version of the PALMS once all the translations were considered idiomatically, semantically, and culturally equivalent. The last draft was pre-tested with a sample of 30 recreational exercisers to assess clarity. Based on the feedback, changes were made, and a final version of the Farsi PALMS was established, which was subsequently validated with 406 volunteer adult participants. The results indicated that the internal consistency for each subscale of the Farsi version of the PALMS varied between .62 and .88 , with the homogeneity of the whole PALMS being .91 . The Farsi version of the PALMS also showed strong test-retest correlations ranging from .84 to .94. An EFA revealed 9 factors: competition/ego, appearance, others' expectations, affiliation, psychological condition, enjoyment, mastery, financial gain, and to be with others. This is consistent with the results from the Hebrew version of the PALMS cited by Zach et al. (2012), who also reported nine factors. However, it was found that the loading of the items on each factor was more similar to the original 8-factor structure that was reported by Morris and Rogers (2004) for the original PALMS. Overall, Zarei et al. (2016) demonstrated that the Farsi version of the PALMS was a reliable and valid instrument that could be used in future research focusing on PA in Iran.

The PALMS has also been translated into Malay using a confirmatory approach (Kueh et al., 2017). This scale, the PALMS-Malay (PALMS-M), was ad- ministered to 634 university undergraduate students. A modification of the path model in a CFA by deleting two problematic items and adding a covariance between items' error for two items resulted in improved fit indices (CIfitRMSEA $=1.00, \mathrm{CFI}=0.91$, TLI $=0.90$, RMSEA $=0.04)$. Although the final measurement model for the PALMS-M consisted of 38 items, it retained the 8-factor structure of the original PALMS. Similarly, the PALMS was also translated into Thai. The PALMS Thai (PALMS-T) was administered to 739 university students (Kuan, Bhasavanija, Abdullah, Morris, \& Kueh, 2018). CFA results indicated that the hypothesized model resulted in a good fit to the data with acceptable levels of fit indices $(\mathrm{CFI}=0.92$, $\mathrm{TLI}=0.91$, RMSEA $=0.06$ ). The final measurement model of the PALMS-T also demonstrated moderate to good construct reliabilities (values ranging from .68 to .91 ) and sound discriminant validity (values for subscale correlations were below .85). Overall, the PALMS-T retained the 8 -factor structure and 40 items of the original PALMS and it was demonstrated to be a reliable and valid instrument for measuring participation motivation in a Thai context. Moreover, researchers have also reported using the translated version of the PALMS in Japanese and Mandarin languages (Machida, Yamada, Araki, \& Tsuchiya, 2013; Wang, Morris, Khoo, Hu, \& Tang, 2013). Overall, the majority of the international validation studies have reported adequate fit to the 40 -item, 8-factor structure of the PALMS, indicating strong support for its reliability and validity across diverse cultures and languages.

\section{DEVELOPMENT OF THE YOUTH PALMS}

In early research with the PALMS, samples included children and youth, alongside adults (Roychowdhury, 2012; Zach et al., 2012). No problems were observed, probably because the majority of participants were adults. However, in a study conducted in Finland, in which all the participants were 16- to 18-year-old adolescents at a sport school, the others' expectations motive did not resolve in the CFA (Aypar, Ruiz, \& Morris, 2017). Examination of items in the others' expectations motive indicated that most related to being paid to perform, which was not relevant to these adolescents, while another item referred to participating to treat a chronic health condition, which again did not apply to healthy sport school students. Consistent "strongly disagree" responses by this sample confirmed the problem. In addition, a 40-item scale might be rather long for younger children, leading to boredom or fatigue. It was evident that a modified version should be more effective for children and adolescents. Hu, Morris, and Lyu (2019) examined a 35-item version of the PALMS, in which the five others' expectations motive items were re- 
moved. They administered this version to a sample of 232 Chinese children and adolescents between 12 and 15 years of age. The 7-motive model was confirmed in EFA, and $\alpha$ coefficients between .79 and .92 supported internal consistency. Hu et al. (2019) then conducted a study with 434 Chinese children and adolescents, aged 14 to 16 years, using a 28 -item version, in which they removed the least-strong item from each 5-item subscale, based on item analysis of the data from the previous study. This left four items on each of seven motive subscales. The reliability and validity results were sound, with strong fit indices in CFA and $\alpha$ coefficients between .82 and .93 . $\mathrm{Hu}$ et al. (2019) proposed this as the PALMS for Youth (PALMS-Y). The PALMS-Y has also been used successfully in a study of Malaysian adolescents (Kueh, Abdullah, Kuan, Morris, \& Naing, 2018).

\section{DEVELOPMENT OF THE PALMS FOR EXTREME SPORTS}

During the period of development of the PALMS, evidence was growing to indicate that participation in traditional forms of sport and PA was, on the whole, declining (WHO, 2020a, c), whereas what had come to be termed "extreme sports" was showing a steady increase in participation (Hajkowicz, Cook, Wilhelmseder, \& Boughen, 2013). This is of particular interest for researchers studying motives for participation in physical activity. A primary question raised relates to the motives that underlie the increase in extreme sports participation that are not satisfied by involvement in traditional sports and PA, which appears to be on the decline. The researchers realized that by simply applying the PALMS to extreme sports, they ran the risk of missing important motives that were not captured by the qualitative studies underlying questionnaires, such as the PMQ and the PALMS, which had asked traditional sports participants to describe their motives. Zhou, Chlebosz, Tower, and Morris (2019) conducted a qualitative study among high-level Chinese extreme sport participants, focusing their open-ended questions on the reasons why they participated. In thematic content analysis of the participants' responses, conducted from an inductive perspective, Zhou et al. (2019) identified seven of the eight motives in the PALMS. Only the appearance motive did not emerge. This was not surprising given that most of the participants were involved in sports such as rock climbing and mountaineering, where appearance would have little relevance. Two new motives did emerge, namely vertigo and catharsis. These motives correspond to those in work by Kenyon (1968) on what he termed attitudes to physical education. Vertigo can be described as doing an activity for the thrill, risk, danger, or excitement. Catharsis involves the refreshment of the spirit associated with completing an extreme activity in which one's personal resources, perhaps even one's life and limb, are tested. Zhou et al. (2019) developed five items to measure each of vertigo and catharsis and, following a validation process, included them in a reordered 50-item, 10-motive PALMS. The new, broader PALMS is in the process of validation and use to compare motives for participation in PA between traditional and extreme sports. The researchers are also examining types of activity within those two main categories, namely traditional and extreme physical activity.

\section{PALMS RESEARCH}

It is conventional to examine variations in psychological variables related to demographic variables, particularly gender and age. However, there have been limited studies examining variations between levels of PALMS motives in terms of demographic variables. A number of studies report descriptive statistics (means, SDs) for major demographic variables, but few have directly tested hypotheses related to gender or age. Molanorouzi, Khoo, and Morris (2015a) compared adult PALMS motives in a study of 657 female and 703 male PA participants in Malaysia. Using DFA to distinguish between levels of motives for the two genders, they found that females were more motivated than males by appearance and physical condition, whereas males were more motivated by competition and mastery. An interesting study by Kueh et al. (2018) examined the measurement and factorial structure invariance of the PALMS-Y across gender in adolescents. Kueh et al. (2018) reported that there was no variance between genders. Invariance is an important question for future studies to examine, in different populations and for various demographic variables. This is because it is only when there is invariance between variables such as gender that it is meaningful to compare male and female samples for differences between motives in diverse contexts with confidence that the statistical differences do not reflect inherent differences in the way that the different genders respond to the items in the scale that was administered.

Different age groups have been compared in some studies, but samples are rarely large enough to test across the lifespan. It is possible to compare data from different studies that have used the adult PALMS with different age cohorts, but comparisons of this kind are likely to be confounded by extraneous factors that vary from study to study. In earlier work, using a version of the PMQ (Gill et al., 1983) that measured motives corresponding to the PALMS with many similar items, Morris, Clayton, Power, and Song (1996b) conducted DFA among a large sample of 2,601 Australians, ranging in age from 10 to 80 years. Morris et al. (1996b) reported that adolescents were discriminated by a strong motive to master new
Role of motives for participation in physical activity 
Tony Morris,

Dev

Roychowdhury skills, young adults by a strong motive to compete, adults by a motive to maintain health, mid-life adults by a motive to cope with stress, and older adults by a motive to manage chronic health conditions. Most studies that have applied the PALMS have not systematically sampled participants to cover the breadth of age that would allow them to test predictions about age differences. Molanorouzi et al. (2015a) grouped their sample of 1,360 Malaysian PA participants into two broader age categories, young adults, who were 20 - to 40-year-olds $(n=763)$ and middle-aged adults, who were 41 - to 64 -year-olds $(n=597)$. DFA indicated that the young adults were more motivated by affiliation, mastery, and enjoyment, whereas the middle-aged adults were more motivated by psychological condition and others' expectations.

Noteworthy findings have emerged from research on characteristics related to PA. A potentially fruitful proposition is that primary motives for participation will vary for different types of PA. However, examining types of PA to determine whether the primary motives vary in a meaningful way between them is fraught with methodological problems. As with age and gender, to identify significant differences requires a very large sample, given that there are a large number of different types of activity. Further, the sheer diversity of sports and non-competitive PA modalities means that it is very difficult to produce an incontrovertible categorical system. In a large Australian study $(N=2,601)$ using PMQ, Morris et al. (1996b) systematically gathered data from five a priori categories that they generated. In DFAs, they found that racquet sport participants (tennis, table tennis, squash) were strongly motivated by competition, team ball sports participants (AFL, basketball, hockey, lacrosse) by affiliation, non-competitive PA participants (aerobics, gym circuit training) by the health motive, and martial arts participants (karate, taekwondo, tai chi) by mastery, while individual body movement activity participants (swimming, gymnastics) were not discriminated. One problem with this categorization is that major activities that would be classified in each of the categories were not examined. Another is that some activities that were classified together might not have a lot in common, for example, aerobics and circuit training. It is likely that this was the problem with the category rather vaguely labelled "body movement" sports. On reflection, it is evident that gymnastics is an artistic sport that is scored by judges, whereas swimming is a racing sport, in which the result is determined by "first past the post", in this case first to touch the wall. In future research, gymnastics might more meaningfully be grouped with other sports judged on technical and artistic merit, including trampolining, figure skating, and diving, whereas swimming could be categorized with other racing sports, such as track athletics and cycling. In a smaller Australian study, of necessity, participants were chosen to represent the five different PA types (Roychowdhury, 2012, 2018a; Roychowdhury \& Morris, 2013). Administering the adult PALMS, Roychowdhury examined motives in AFL, gym-based exercise, tennis, taekwondo, and yoga. Using DFA, it was found that AFL participants were discriminated by higher affiliation and lower others' expectations and appearance motives than the rest of the sample, gym-based exercisers by higher appearance and lower others' expectations motives, tennis participants by higher competition/ego and lower others' expectations motives, taekwondo participants by higher mastery and enjoyment and lower others' expectations and appearance motives, and yoga participants by higher mastery and psychological condition and lower others' expectations, affiliation, and competition/ego motives than the rest of the sample. In a more recent study, also using the PALMS, Molanorouzi et al. (2015a) asked 1,360 individuals to name their main PA as they completed the PALMS. Then the activities were grouped by three researchers independently and activity categories were arrived at by consensus. The range of popular physical activities fell into the same five categories as in the Morris et al. (1996b) study, except that this time an individual racing sports category emerged. Once again, the PALMS data were then analyzed using DFA. Molanorouzi et al. (2015a) reported that racquet sport participants were discriminated by higher mastery and competition motives than the rest of the sample, team ball sport participants by higher affiliation and mastery, non-competitive exercise participants by higher psychological condition, appearance and physical condition motives, but lower mastery and competition motives, martial arts participants by higher competition, mastery and psychological condition motives, and individual racing participants by higher enjoyment, with lower appearance and affiliation motives than the rest of the sample.

Valuable research has been conducted identifying motives and describing their patterns in relation to demographic variables, including gender and age, as well as distinguishing between motivational profiles typical of different types of PA. Nonetheless, the bottom line for the application of motives to enhance participation relates to the question of whether motives for participation in PA are associated with higher levels of active participation in PA. Molanorouzi et al. (2015b) examined this in a study involving 489 male undergraduate students. They completed the adult PALMS and the International Physical Activity Questionnaire (IPAQ) on two occasions 14 weeks apart. This allowed the researchers to perform concurrent and predictive tests in both directions. Because major motives had been shown to differ with types of activity, the sample was separated into three types of activity, namely racquet sports, team ball sports, and exercisers. The key correlations referred to motives on Occasion 1 and PA on Oc- 
casion 2 because this reflected the extent to which motives were associated with PA 14 weeks later. For racquet sport players, the highest correlations of motives with IPAQ MET-minutes per week were for competition $(r=.65)$ and mastery $(r=.64)$. For team ball sports, the highest correlations were for affiliation $(r=.73)$ and mastery $(r=.71)$. For exercisers, the highest correlations were for psychological condition $(r=.69)$ and enjoyment $(r=.67)$. Based on Cohen's (1988) determination that effect sizes for Pearson's product-moment correlation coefficient are large if they are $r=.5$ or above, for each activity sub-sample, the correlations between two motives and actual PA were found to show large effect sizes. These findings support the main hypothesis of the Molanorouzi et al. (2015b) study that motives for participation in PA predicted the amount of PA individuals undertook 14 weeks later. They also reflect the expectation that the primary motives vary depending on the type of PA in which individuals participate, as suggested in the DFA studies of activity types reported previously (Molanorouzi et al., 2015a; Morris et al., 1996b; Roychowdhury, 2012; Roychowdhury \& Morris, 2013).

Abdullah et al. (2019) conducted another study that examined the relationship between motives for participation in PA and amount of PA. To examine this relationship, Abdullah et al. (2019) administered the PALMS-Y and the Godin-Shephard Leisure-time Physical Activity Questionnaire (Godin, 2011) in Chinese to 304 Chinese secondary school students $($ male $=165$; female $=139)$ in Kelantan, Malaysia . Abdullah et al. (2019) found significant positive correlations between all seven motives in the PALMS-Y and the Godin scale. The highest correlations were for psychological condition $(r=.27)$, mastery $(r=.22)$, and affiliation $(r=.22)$. The correlations in this study were lower than those found in the Molanorouzi et al. (2015b) study. This could partly be explained by failure to control the type of PA variable, which seems to moderate the relationship between motives and amount of physical activity. Participants in the Abdullah et al. (2019) study comprised a convenience sample of 12 - to 15-year-old students who volunteered to complete the questionnaires. Thus, they represented participants in diverse popular sports, including a mix of team ball sports, racquet sports, individual body movement sports, martial arts, and non-competitive exercise activities, which doubtless created noise in the data. Nonetheless, the key motives from the Molanorouzi et al. (2015b) study were prominent. The early studies of motives and amount of PA are indicative, but it is important for researchers to conduct larger, more sophisticated, well-controlled studies on this critical issue.

In a new direction for research on motives for participation in PA, researchers are seeking to understand the roles of other psychological variables in the relationship between motives and amount of PA. Ex- amining possible antecedents of motives is important for the effectiveness of interventions that enhance motives. Research on variables that have the potential to mediate between motives and amount of PA is equally crucial. One psychological variable could be an antecedent of motives or a mediator. Bandura (1977) proposed that self-efficacy influences motivation. When self-efficacy for a behavior or task is high, people are motivated to perform that task, whereas when self-efficacy is low, individuals avoid the task. Also, self-efficacy can mediate between psychological variables and behavior (Mansouriyeh, Poursharifi, Sadeghi, \& Seirafi, 2017; Thomas, Muralidharan, Medoff, \& Drapalski, 2016). Thus, it is possible that even when motives are high, individuals still do not perform the task, because self-efficacy is low, that is, if those individuals have a low level of confidence (Axelsson, Lötvall, Cliffordson, Lundgren, \& Brink, 2013; de Souza, Torres, Barbosa, de Lima, \& de Souza, 2014). To examine the role of self-efficacy, Yoo et al. (2018) administered the PALMS, the Exercise Self-efficacy Scale (ESES; McAuley, 1993), and the Barriers Self-efficacy Scale (BARSE; McAuley, 1992) to a sample of 384 Korean adult participants. Using structural equation modelling (SEM), Yoo et al. (2018) generated and tested two models. In the first, the two aspects of self-efficacy were portrayed as antecedents of motives for participation. In the second model, the self-efficacy variables were presented as mediators of self-efficacy for PA. SEM indicated that self-efficacy was a significant mediator, but not a significant antecedent of motives for participation in PA. In a similar study, with 666 12- to 18-year-old adolescents in China, Hu, Kueh, and Morris (2018) administered the PALMS-Y, ESES, BARSE, and the Godin-Shephard Leisure-time Physical Activity Questionnaire (Godin, 2011). Again, Hu et al. (2018) tested a model in which self-efficacy was an antecedent of motives, which then influenced PA, and a model in which motives influenced PA through the mediation of self-efficacy. Once more, it was the barriers aspect of self-efficacy that proved significant. Physical condition and competition-ego motives influenced the amount of PA, but both were mediated by barriers to self-efficacy. Thus, it was only when individuals were confident that they could overcome a range of barriers to participate in their chosen activity that their motive to maintain or enhance their physical condition and their motive to compete to show their competence led them to undertake a larger amount of PA. Research on the role of self-efficacy in the relationship between participation motives and PA has just begun, but shows early potential to be informative.

Another variable that is considered to enable motivational tendencies is mindfulness (Roychowdhury \& Morris, 2019; Roychowdhury, Morris, \& Spittle, 2018). Research on participation motivation and dispositional mindfulness has shown promising results.
Role of motives for participation in physical activity 
Tony Morris,

Dev

Roychowdhury
Exploring the associations between mindfulness and health behaviors, researchers have found that students who report higher scores of self-reported mindfulness appear to have higher motivation to practice healthy habits, such as getting enough sleep, eating well, and exercising, compared to those students who report lower scores. (Gilbert \& Waltz, 2010; Murphy, Mermelstein, Edwards, \& Gidycz, 2012; Roberts \& Danoff-Burg, 2010). Studies have also shown that mindfulness-based programs that help participants change their approach to their thoughts and emotions about obesity resulted in lower psychological distress, greater weight loss, and an increase in PA (Lillis, Hayes, Bunting, \& Masuda, 2009; Tapper et al., 2009). Thus, by becoming aware of their thoughts, emotions, and sensations due to behavior change, and by accepting them, individuals showed heightened awareness of good health behavior (Dutton, 2008). Although it is evident that mindfulness skills and motivational regulation favor higher PA levels, the direction and intensity of this relationship are not known. For instance, on one hand, studies have found that the highest scores of mindfulness and acceptance are linked to a long-term PA increase and maintenance (Chatzisarantis \& Hagger, 2007; Ulmer, Stetson, \& Salmon, 2010). On the other hand, Mothes, Klaperski, Seelig, Schmidt, and Fuchs (2014) found in a randomized controlled trial that an aerobic exercise intervention increased self-reported mindfulness in men. Thus, future research in this domain should examine the relationship between mindfulness and motivation and explore how that relationship affects PA levels.

Passion is a variable that has recently attracted increasing attention in sport and exercise, as well as in areas including education and business. This is largely due to the work of Vallerand (Vallerand, 2008, 2010, 2012, 2015; Vallerand et al., 2003), who proposed a dualistic model of passion, comprising harmonious passion (HP) and obsessive passion (OP). Passion is conceived to be an intense attraction to an object or behavior, leading individuals to be highly motivated to perform the behavior. Thus, passion is considered to be related to intrinsic motivation, representing the extreme form of motivation, in which the behavior has been integrated into individuals' personality. Clearly, passion is closely related to motives for participation in PA. Habib, Khoo, and Morris (submitted) conducted a preliminary investigation of the relationship between passion, participation motives, and physical activity. Habib et al. (submitted) administered Urdu versions of the Passion Scale (Vallerand et al., 2003), which measures HP and OP, the PALMS, and the IPAQ to 572 adults in Pakistan. HP showed high positive correlations with all eight PALMS motives, whereas OP showed low negative correlations with all PALMS motives. In multiple hierarchical regression analysis, PALMS mastery and physical con- dition motives and HP were significant predictors of overall physical activity. This study suggests that PALMS and HP are closely related and together they can predict greater variance in PA $(26 \%)$ than they do separately, showing promise for further research.

In conclusion, research on a range of issues related to motives for participation in PA is in its early stages, but most issues that have been addressed show promise for further research. Such research should increase understanding of the variables that motives affect, those variables that affect motives, and those variables that mediate the effect of motives on important outcome variables, particularly the actual amount of PA people do. Examining the relationship between motives and PA should be the primary focus of research in the near future.

\section{MOTIVATIONAL PROFILING}

There is now strong evidence that PA plays a major role in promoting physical health and psychological wellbeing and that motivation is a strong predictor of participation in PA. Given that around half the global adult population do not do sufficient, sustained PA to achieve health benefits (WHO, 2020b) and children and adolescents' participation in traditional forms of PA and sport are also declining (Hu et al., 2018), promoting long-term adherence to and involvement in PA is vitally important. Thus, it is essential to measure motives for participation and relate them to patterns of participation. This will not only help promote motives that enhance participation in PA, but also help match motivational patterns to appropriate forms of PA.

Researchers have reported that different patterns of motives are associated with participation in different types of PA (e.g., Molanorouzi et al., 2015a). It is, therefore, essential for researchers and practitioners to develop and implement techniques to advise individuals about the type of PA that their patterns of motives for PA participation indicate is likely to lead to long-term participation at levels sufficient to achieve satisfaction and promote health and wellbeing. As a valid and reliable measure of motives for participation, the PALMS has demonstrated a solid 8-factor structure that could be used to advise individuals about the kinds of activities that they are likely to find will satisfy their motives for PA. Using a consistent and systematic approach of displaying results of tests for participation in different kinds of PA, the patterns of motives for PA participation using the PALMS can be presented as profiles (Morris, Roychowdhury, \& Khoo, 2019). This type of motivational profiling can then be used to advise people about the kinds of activities that they are likely to find will satisfy their motives for PA. Morris et al. (2019) argue that such motivational profiles should clearly present the sequence of motives and 
their relationships with PA in a manner that would also allow for easy comparisons across groups, conditions, and factors. Based on the 8-motive format that has been consistently derived from PALMS research, we propose that the sequence of motives should be displayed based on their intrinsic to extrinsic motivation orientation and should follow the order: mastery, enjoyment, psychological condition, physical condition, appearance, others' expectations, affiliation, and competition/ego. A standard way of sequencing motives in a profile, displaying intrinsic motives on the extreme left to extrinsic motives on the extreme right, is presented in Figure 2.

Researchers and health practitioners should use the PALMS to create motivational profiles to advise individuals on the type of PA in which they should participate to obtain desired health benefits, enhance satisfaction, and improve long-term adherence (Morris \& Roychowdhury, 2015; Morris et al., 2019). For instance, individuals whose PALMS profile indicates a strong affiliation motive might be advised to participate in team sports to satisfy their need for social relationships. Similarly, individuals who display a profile in which competition/ego is prominent might be advised to participate in PA involving head-to-head competition. For instance, Figure 2 depicts a hypothetical PALMS profile for individuals who display a strong appearance motive. Based on the motivational profile, these individuals might be advised to participate in gym-based PA to satisfy their need to make their body look the way they want it to.

This kind of profiling and matching will not only maximize satisfaction; it will also reduce drop-out, a phenomenon that is prevalent in sport at many levels, and in the health and fitness industry. Profiling could also allow health practitioners to monitor changes in motivation that individuals might display over a period of time. For instance, individuals diagnosed with obesity and recommended to undertake gym-based exercise by their doctor or family might initially display a high others' expectations profile on PALMS. But with consistent effort and results in the gym, the same individuals, in a matter of a few months, might become more motivated to improve their body shape. It would be plausible to argue that the PALMS profile for such individuals might look different with appearance or physical condition prominent. Despite the fact that human motivation or engagement in PA is rarely a linear process, existing questionnaires in the PA literature fail to acknowledge this, and hence they are limited in their applicability. The creation of motivational profiles, using the PALMS in this domain, has noteworthy implications. Health practitioners and consultants could use the PALMS to create and monitor motivational profiles for individuals. These motivational profiles could not only be used to inform individuals about their primary participation motives and ap-

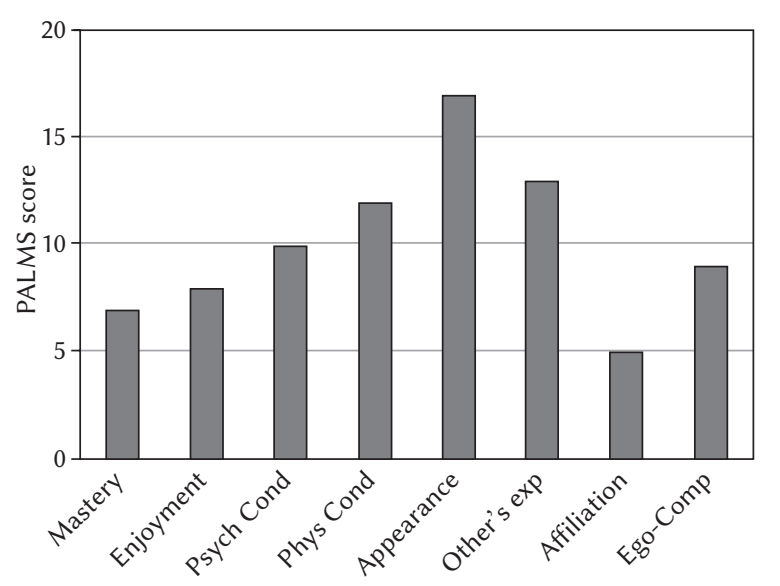

Role of motives for participation in physical activity

Note. From "Motives for participation in physical activity:

Measurement, prediction, and profiling." by T. Morris \& D. Roychowdhury, 2015, Paper presented at $14^{\text {th }}$ European Federation of Sport Psychology Congress, Bern, Switzerland (https://boris. unibe.ch/71978/1/FEPSAC\%20CONGRESS\%202015\%20Proceedings.pdf). Copyright T. Morris \& D. Roychowdhury.

Figure 2. Sequence of motives in PALMS profile.

propriate motives-PA match, but also monitor their progress over a period of time to ensure that they are able to maximize their satisfaction and obtain desired health benefits.

\section{USING MOTIVES FOR PARTICIPATION TO ENHANCE PHYSICAL ACTIVITY FOR HEALTH}

Research that has been conducted to examine the relationship between motives for participation in PA and the amount of PA people do is limited to date. As reported in the previous section, initial studies suggest that certain motives do influence how much PA people do (Abdullah et al., 2019; Molanorouzi et al., 2015b), and that the crucial motives vary depending on the type of PA (Molanorouzi et al., 2015b). Further research should be conducted with large and diverse samples to verify these early findings. Nonetheless, if the relationship between motives for participation in PA and the amount of PA people do is confirmed, participation motives could be important factors to consider when aiming to increase PA for health among various populations. Here we propose two approaches that could be applied to develop understanding of the role of participation motives in PA promotion. The first approach involves matching motives to types of $\mathrm{PA}$, and the second approach involves using interventions to enhance the levels of targeted motives, high levels of which are expected to lead to increases in the amount of PA that people undertake.

Based on the increasing evidence that high levels of specific motives are related to higher levels of PA participation (Abdullah et al., 2019; Molanorouzi et al., 
Tony Morris,

Dev

Roychowdhury
$2015 b)$ and that distinct motives play a primary role in different types of PA (Molanorouzi et al., 2015a; Morris et al., 1996b; Roychowdhury, 2012, 2018a, b, 2020), one reason why many people do not maintain their participation in activities over the long term is that they choose activities that do not satisfy their motives for participating. For example, individuals with a high competition-ego motive, of which they are not aware, might join a non-competitive exercise program because it is local and easily accessible, but soon drop out because it does not provide the opportunity for them to compete. Another example could be that people with a strong, but unconscious, motive to participate in PA to improve their appearance might be encouraged by friends to join a local sport team, only to find that the team is invested in a culture of postgame beer and kebabs. Many people might not even start to participate because the options that seem to be available to them appear unattractive, but they have no idea what activity they would like to join. It is possible that all these problems could be resolved by matching motives with activity type.

Increasing evidence indicates that specific motives discriminate one type of PA from others (Molanorouzi et al., 2015a; Morris et al., 1996b; Roychowdhury, 2012, 2018a, b, 2020; Roychowdhury \& Morris, $2013,2019)$ and that each type of PA displays a distinct pattern or motivational profile (Morris \& Roychowdhury, 2015; Morris et al., 2019). Individuals who have tried certain types of PA and felt dissatisfied or those who do not know which type of PA to choose could be helped by completing the PALMS, on the basis of which they could be given generic advice that might help them to select an activity that would suit them. For example, based on evidence from the motives and type of PA studies, individuals with a strong motive for affiliation would be advised that they might find satisfaction by participating in a group activity. If a secondary motive favored noncompetitive exercise, the advice might focus more on group exercise activities, whereas were secondary motives to indicate an interest in competition-ego, competitive team sports could be recommended. Another example might be individuals whose primary motive is mastery. The advice in this case would be for those individuals to select an activity in which they would learn new skills, which would open up a wide range of PA. Again, where the secondary motives reflected non-competitive activities, exercise activities involving skill components would be advised, whereas for individuals whose profile was more competitive, individual sports involving skills or competitive martial arts would be suggested. Although there are some clear indications from the research conducted to date, the guidance that is provided will be refined and moderated, as further research on participation motives and types of PA is conducted. It would be interesting to see studies in which this kind of match- ing is conducted with participants in one condition and participants in another condition simply choose their activity based on factors the individuals determine, including ease of access and the influence of friends. Then all participants would be followed up over a substantial period of time, for example, 6 or 12 months, to determine whether there is any difference in the long-term amount of participation and maintenance of the chosen activity.

Strong evidence of the impact of motives on participation in PA could be derived from intervention studies that apply effective techniques to increase the level of key motives for participation in PA and then examine the impact this has on PA participation. Determining whether there are universal key motives, or, perhaps more likely, what the key motives under different contextual conditions are, is a task that has yet to be systematically undertaken. Reflection on the literature to date does suggest that certain motives have been more prominent than others. For example, studies that have examined motives and types of PA using DFA have identified different motives that discriminated in different types of activity (Molanorouzi et al., 2015a; Morris et al., 1996b; Roychowdhury, 2012, 2018a; Roychowdhury \& Morris, 2013). However, when the absolute values of motives were examined in motivational profiles, the intrinsic motive, enjoyment, was found to be high or highest across profiles for most motives (Morris \& Roychowdhury, 2015; Morris et al., 2019; Roychowdhury \& Morris, 2013). Thus, perhaps not surprisingly, individuals' enjoyment of the PA in which they are participating seems to be a strong motive for doing a larger amount of PA than among people who do not have such a high level of enjoyment. Interventions that enhance individuals' enjoyment would thus be predicted to increase their long-term participation in PA. Such interventions might include mastery goal setting designed to increase enjoyment in a stepwise fashion (Benita, Roth, \& Deci, 2014; Puente-Diaz, 2012), imagery of enjoying participation in PA (Kosteli, Williams, \& Cumming, 2018; Stanley \& Cumming, 2010), or positive self-talk reinforcing enjoyment (Hardy, Hall, \& Hardy, 2010). In studies examining the relationship between participation motives and other variables, such as self-efficacy (Yoo et al., 2018) and passion (Habib et al., submitted), mastery has been a prominent motive. Similar interventions to those employed to enhance enjoyment could be developed to promote the mastery motive. For example, mastery goal setting in which the focus is on stepwise increases in performance of a PA skill should be reflected in increases in the mastery motive (Benita et al., 2014), and motivational general mastery imagery (Hall, Mack, Paivio, \& Hausenblas, 1998) has been shown to be effective in increasing individuals' perception of their mastery, which is likely to increase mastery motivation (Hammond, Gregg, Hrycaiko, Mactavish, 
\& Leslie-Toogood, 2012; Koehn, Morris, \& Watt, 2013, 2014). The two examples of enjoyment and mastery were chosen because they emerged from research pertinent to the issue of identifying key motives for participation in PA that would be worthy of intervention. Perhaps it is not coincidental that they are the two motives that reflect intrinsic motivation, based on Deci and Ryan's (1985) SDT. Intrinsic motivation has been shown to lead to maintenance of behaviors, such as PA, in the long term (Ryan et al., 1997; Teixeira, Carraça, Markland, Silva, \& Ryan, 2012), which is a major aim of programs that promote long-term PA for health. Thus, mastery and enjoyment, the two intrinsic motives in PALMS, appear to be important variables for researchers to examine further. Research on interventions to enhance motives for participation in PA that aims ultimately to increase participation in PA has yet to be initiated. However, there is great potential in such research. We encourage researchers to explore this type of intervention research.

\section{CONCLUSIONS}

Despite the well-documented benefits of engaging in regular PA, global estimates indicate that participation in PA around the world is declining. This is a source of major concern. Declining participation in PA not only means that people are unable to obtain the desired health benefits, but it also suggests that they are more likely to develop health conditions, especially given that lifestyles globally have become exceedingly automated and sedentary. It is, therefore, important to motivate people to engage in PA. More specifically, it is important to understand what motivates people to participate in PA and the factors that influence motives for participation in PA, so that health researchers and practitioners can design appropriate interventions and programs to target inactivity.

Researchers in PA have developed theoretical and atheoretical approaches to examine the reasons people give for engaging in PA. Consequently, a number of questionnaires that aim to measure motives for PA participation have been developed. However, most of these measures have drawbacks and do not comprehensively cover the breadth of motives for PA participation. Building on the limitations of previous questionnaires, we developed the PALMS, which has since been demonstrated to be a reliable and valid measure of motives for participation in PA that can be used across diverse cultures, ages, and languages. Using the PALMS, we have found that people participate in distinct types of PA for different reasons and that their participation in particular PA may be characterized by primary and specific participation motives. These differences have been observed across age, gender, skill level, and amount and type of PA undertaken. Future research in this domain should use the PALMS to examine the relationship between motives for PA participation and extent of participation in different types of PA. In addition, it is important to study psychological variables that can influence motives, such as self-efficacy, mindfulness, and passion, and that could mediate or moderate the motives-PA participation relationship. In the future, it will also be valuable to examine environmental and personal antecedents to motives for participation, such as social and cultural influences during childhood, proximal contextual factors, character, and temperament.

We hope that future research in this domain will help to develop a comprehensive understanding of the various reasons people have for participating in different types of PA. This knowledge will hopefully enable researchers and practitioners to design effective interventions to match motives with appropriate types of PA, thereby enhancing satisfaction and raising levels of targeted motives to increase PA participation around the world. This should lead to people gaining the health benefits they desire and reducing the prevalence of lifestyle-related illnesses.

\section{RefERENCES}

Abdullah, N., Kueh, Y., Hanafi, M., Morris, T., \& Kuan, G. (2019). Motives for participation and amount of physical activity among Kelantan Chinese adolescents. Malaysian Journal of Medical Sciences, 26, 101-110. https://doi.org/10.21315/mjms 2019.26.6.10

Anderson, E., \& Durstine, J. (2019). Physical activity, exercise, and chronic diseases: a brief review. Sports Medicine and Health Science, 1, 3-10. https:// doi.org/doi:10.1016/j.smhs.2019.08.006

Axelsson, M., Lötvall, J., Cliffordson, C., Lundgren, J., \& Brink, E. (2013). Self-efficacy and adherence as mediating factors between personality traits and health-related quality of life. Quality of Life Research, 22, 567-575. https://doi.org/10.1007/s11136012-0181-z

Aypar, E., Ruiz, M., \& Morris, T. (2017, July). Adaptation and validation of the Physical Activity and Leisure Motivation Scale (PALMS) to assess motives for participation in leisure time physical activity and sport in Finnish high-school students. Paper presented at International Society of Sport Psychology 14th World Congress, Sevilla, Spain.

Bandura, A. (1977). Self-efficacy: Toward a unifying theory of behavioral change. Psychological Review, 84, 191-215. https://doi.org/10.1037/0033-295X.84. 2.191

Benita, M., Roth, G., \& Deci, E. (2014). When are mastery goals more adaptive? It depends on experiences of autonomy support and autonomy. Journal of Educational Psychology, 106, 258-267. https://doi.org/10.1037/a0034007
Role of motives for participation in physical activity 
Brodkin, P., \& Weiss, M. (1990). Developmental differences in motivation in competitive swimming. Journal of Sport \& Exercise Psychology, 12, 248-263. https://doi.org/10.1123/jsep.12.3.248

Buonamano, R., Cei, A., \& Mussino, A. (1995). Participation motivation in Italian youth sport. The Sport Psychologist, 9, 265-281. https://doi.org/10.1123/ tsp.9.3.265

Centers for Disease Control and Prevention (2020). Physical activity prevents chronic disease. Re-
Tony Morris,

Dev

Roychowdhury trieved from https://www.cdc.gov/chronicdisease/ resources/infographic/physical-activity.htm\#: : text=Regular\%20physical\%20activity\%20helps\%20 improve,depression $\% 20$ and $\% 20$ anxiety $\% 2 \mathrm{C} \% 20$ and\%20dementia [accessed June 19, 2020]

Chatzisarantis, N., \& Hagger, M. (2007). Mindfulness and the intention-behavior relationship within the theory of planned behavior. Personality and Social Psychology Bulletin, 33, 663-676. https://doi. org/10.1177/0146167206297401

Cohen, J. (1988). Statistical power analysis for the behavioural sciences. Mahwah, NJ: Lawrence Erlbaum Associates.

Deci, E., \& Ryan, R. (1985). Intrinsic motivation and self-determination in human behaviour. New York: Plenum Press.

de Souza, L., Torres, A., Barbosa, G., de Lima, T., \& de Souza, L. (2014). Self-efficacy as a mediator of the relationship between subjective well-being and general health of military cadets. Cadernos de Saúde Pública, 30, 2309-2319. https://doi.org/10.1590/0102$311 \times 00177513$

Dinas, P., Koutedakis, Y., \& Flouris, A. (2010). Effects of exercise and physical activity on depression. Irish Journal of Medical Science, 180, 319-325. https://doi. org/10.1007/s11845-010-0633-9

Duda, J. (1988). Goal perspectives, participation, and persistence in sport. Journal of Sport Psychology, 19, 117-130.

Dutton, G. (2008). The role of mindfulness in health behavior change. ACSM's Health \& Fitness Journal, 12, 7-12. https://doi.org/10.1249/fit.0b013e31817bf5db

Fortier, M., Vallerand, R., Brière, N., \& Provencher, P. (1995). Competitive and recreational sport structures and gender: a test of their relationship with sport motivation. International Journal of Sport Psychology, 26, 24-39.

Frainer, J. (2017). Reasons for joining the practice of physical and sports activities in Brazil. Master's dissertation, Federal University of Santa Catarina, Florianópolis, Brazil.

Frederick, C., \& Ryan, R. (1993). Differences in motivation for sport and exercise and their relations with participation and mental health. Journal of Sport Behaviour, 16, 124-146.

Friedenreich, C., Neilson, H., \& Lynch, B. (2010). State of the epidemiological evidence on physical activity and cancer prevention. European Journal of Cancer, 46, 2593-2604. https://doi.org/10.1016/j. ejca.2010.07.028

Gilbert, D., \& Waltz, J. (2010). Mindfulness and health behaviors. Mindfulness, 1, 227-234. https://doi.org/ 10.1007/s12671-010-0032-3

Gill, D., Gross, J., \& Huddleston, S. (1983). Participation motivation in youth sports. International Journal of Sport Psychology, 14, 1-14.

Godin, G. (2011). The Godin-Shephard Leisure-Time Physical Activity Questionnaire. Health and Fitness Journal of Canada, 4, 18-22. https://doi.org/10.14288/ hfjc.v4i1.82

Gould, D., Feltz, D., \& Weiss, M. (1985). Motives for participating in competitive youth swimming. International Journal of Sport Psychology, 16, 126-140.

Guthold, R., Stevens, G., Riley, L., \& Bull, F. (2018). Worldwide trends in insufficient physical activity from 2001 to 2016: a pooled analysis of 358 population-based surveys with 1.9 million participants. The Lancet Global Health, 6, e1077-e1086. https:// doi.org/10.1016/s2214-109x(18)30357-7

Habib, M., Khoo, S., \& Morris, T. (submitted). Motives and passion of adults from Pakistan toward physical activity. PLOS One.

Hajkowicz, S., Cook, H., Wilhelmseder, L., \& Boughen, N. (2013). The future of Australian sport: Megatrends shaping the sports sector over coming decades. Belconnen, ACT: Commonwealth Scientific and Industrial Research Organisation.

Hall, C., Mack, D., Paivio, A., \& Hausenblas, H. (1998). Imagery use by athletes: Development of the Sport Imagery Questionnaire. International Journal of Sport Psychology, 29, 73-89.

Hammond, T., Gregg, M., Hrycaiko, D., Mactavish, J., \& Leslie-Toogood, A. (2012). The effects of a motivational general-mastery imagery intervention on the imagery ability and sport confidence of intercollegiate golfers. Journal of Imagery Research in Sport and Physical Activity, 7, 3. https://doi.org/ 10.1515/1932-0191.1066

Hardy, J., Hall, C., \& Hardy, L. (2010). A note on athletes' use of self-talk. Journal of Applied Sport Psychology, 16, 251-257. https://doi.org/10.1080/ 10413200490498357

Hu, L., Kueh, Y. C., \& Morris, T. (2018, July). Selfefficacy mediates the influence of motives for participation on physical activity participation among adolescents. Paper presented at 8th Asian South Pacific Association of Sport Psychology International Congress, Daegu, South Korea.

Hu, L., Morris, T., \& Lyu, J. (2019). Revision and validation of the Physical Activity and Leisure Motivation Scale among youth in China. International Journal of Sport Psychology, 50, 38-63. https://doi. org/10.7352/IJSP.2019.50.038.

Kenyon, G. (1968). Six scales for assessing attitudes towards physical activity. Research Quarterly, 39, 566574. https://doi.org/10.1080/10671188.1968.10616581 
Kirkby, R., Kolt, G., \& Liu, J. (1999). Participation motives of young Australian and Chinese gymnasts. Perceptual and Motor Skills, 88, 363-373. https:// doi.org/10.2466/pms.1999.88.2.363

Klint, K., \& Weiss, M. (1987). Dropping in and dropping out: Participation motives of current and former youth gymnasts. Canadian Journal of Applied Sport Sciences, 11, 106-114.

Koehn, S., Morris, T., \& Watt, A. (2013). Flow state in self-paced and externally-paced performance contexts: an examination of the flow model. Psychology of Sport and Exercise, 14, 787-795. https:// doi.org/10.1016/j.psychsport.2013.06.001

Koehn, S., Morris, T., \& Watt, A. (2014). Imagery intervention to increase flow state and performance in competition. The Sport Psychologist, 28, 48-59. https://doi.org/10.1123/tsp.2012-0106

Kolt, G., Kirby, R., Bar-Eli, M., Blumenstein, B., Chadha, N., Liu, J., \& Kerr, G. (1999). A cross-cultural investigation of reasons for participation in gymnastics. International Journal of Sport Psychology, 30, 381-398.

Kosteli, M., Williams, S., \& Cumming, J. (2018). Exploring imagery as a technique for promoting physical activity in older adults. Imagination, Cognition and Personality, 38, 405-424. https://doi. org $/ 10.1177 / 0276236618767083$

Kueh, Y., Abdullah, N., Kuan, G., Morris, T., \& Naing, N. (2018). Testing measurement and factor structure invariance of the Physical Activity and Leisure Motivation Scale for Youth across gender. Frontiers in Psychology, 9, 1096. https://doi.org/ 10.3389/fpsyg.2018.01096

Kueh, Y., Kuan, G., \& Morris, T. (2017). The Physical Activity and Leisure Motivation Scale: a confirmatory study of the Malay language version. International Journal of Sport and Exercise Psychology, 17, 250-265. https://doi.org/10.1080/1612197X. 2017.1321029

Kuan, G., Bhasavanija, T., Abdullah, N., Morris, T., \& Kueh, Y. C. (2018, July). The Physical Activity and Leisure Motivation Scale in Thai language: a confirmatory factor analysis. Paper presented at 8th Asian South Pacific Association of Sport Psychology International Congress, Daegu, Korea.

Lewis, B., Napolitano, M., Buman, M., Williams, D., \& Nigg, C. (2016). Future directions in physical activity intervention research: Expanding our focus to sedentary behaviors, technology, and dissemination. Journal of Behavioral Medicine, 40, 112126. https://doi.org/10.1007/s10865-016-9797-8

Li, F. (1999). The Exercise Motivation Scale: Its multifaceted structure and construct validity. Journal of Applied Sport Psychology, 11, 97-115. https:// doi.org/10.1080/10413209908402953

Lillis, J., Hayes, S., Bunting, K., \& Masuda, A. (2009). Teaching acceptance and mindfulness to improve the lives of the obese: a preliminary test of a theo- retical model. Annals of Behavioral Medicine, 37, 58-69. https://doi.org/10.1007/s12160-009-9083-x

Longhurst, K., \& Spink, K. (1987). Participation motivation of Australian children involved in organized sport. Canadian Journal of Sport Sciences, 12, 24-30.

Machida, M., Yamada, H., Araki, K., \& Tsuchiya, H. (2013). A preliminary examination of the relationship between physical activity motivation and self-efficacy among physical activity participants in Japan. Paper presented at International Society of Sport Psychology 13th World Congress, Beijing, China.

Mansouriyeh, N., Poursharifi, H., Sadeghi, M., \& Seirafi, M. (2017). Self-efficacy as a mediator in the relationship between social support and self-care in patients with heart failure. International Journal of Medical Research and Health Sciences, 6, 157-162.

Markland, D., \& Hardy, L. (1993). The exercise motivations inventory: Preliminary development and validity of a measure of individuals' reasons for participation in regular physical exercise. Personality and Individual Differences, 15, 289-296. https://doi.org/10.1016/0191-8869(93)90219-S

Markland, D., \& Ingledew, D. (1997). The measurement of exercise motives: Factorial validity and invariance across gender of a revised Exercise Motivation Inventory. British Journal of Health Psychology, 2, 361-376. https://doi.org/10.1111/j.2044-8287.1997. tb00549.x

McAuley, E. (1992). The role of efficacy cognitions in the prediction of exercise behavior in middle-aged adults. Journal of Behavioral Medicine, 15, 65-88. https://doi.org/10.1007/BF00848378

McAuley, E. (1993). Self-efficacy and the maintenance of exercise participation in older adults. Journal of Behavioral Medicine, 16, 103-113. https://doi.org/ 10.1007/BF00844757

Molanorouzi, K., Khoo, S., \& Morris, T. (2014). Validating the Physical Activity and Leisure Motivation Scale (PALMS). BMC Public Health, 14, 909. https:// doi.org/10.1186/1471-2458-14-909

Molanorouzi, K., Khoo, S., \& Morris, T. (2015a). Motives for adult participation in physical activity: Type of activity, age, and gender. BMC Public Health, 15, 66. https://doi.org/10.1186/s12889-015-1429-7

Molanorouzi, K., Khoo, S., \& Morris, T. (2015b). The relationship between motivation for physical activity and level of physical activity over time. International Journal of Medical, Health, Biomedical, Bioengineering and Pharmaceutical Engineering, 9, 609-612.

Morris, T. (2019, July). Motives for participation in sport and physical activity: Introduction. In T. Morris (Chair), Motives for participation in sport and physical activity: New approaches (Symposium). 15th European Congress of Sport and Exercise Psychology, Munster, Germany.

Morris, T., Clayton, H., Power, H., \& Han, J. (1995). Activity type differences in participation motives. Australian Journal of Psychology, 47, 101-102.
Role of motives for participation in physical activity 
Morris, T., Clayton, H., Power, H., \& Han, J. (1996a, August). Participation motivation for different types of physical activity. Poster presented at International Pre-Olympic Congress, Texas, USA.

Morris, T., Clayton, H., Power, H., \& Song, H. (1996b). Motives for participation in selected physical activities in Australia. Technical report to the Australian Sports Commission. Canberra: ASC.

Morris, T., \& Han, J. (1991). Motives for taking up taichi. Paper presented at 1st Asian South Pacific As-

Tony Morris,

Dev

Roychowdhury sociation of Sport Psychology International Congress, Melbourne, Australia.

Morris, T., Power, H., \& Pappalardo, B. (1993, June). Motivation for participation in table tennis. Paper presented at 8th World Congress in Sport Psychology, Lisbon, Portugal.

Morris, T., \& Rogers, H. (2004). Measuring motives for physical activity. Sport and Chance of Life: Proceedings of 2004 International Sport Science Congress (pp. 242-250). Seoul: KAHPERD.

Morris, T., \& Roychowdhury, D. (2015, July). Motives for participation in physical activity: Measurement, prediction, and profiling. Paper presented at 14th European Federation of Sport Psychology Congress, Bern, Switzerland. Retrieved from https://boris.unibe.ch/71978/1/FEPSAC\%20CONGRESS\%202015\%20Proceedings.pdf

Morris, T., Roychowdhury, D., \& Khoo, S. (2019, July). Applying motivational profiling in sport and physical activity. In T. Morris (Chair), Motives for participation in sport and physical activity: New approaches (Symposium). 15th European Congress of Sport and Exercise Psychology, Munster, Germany.

Mothes, H., Klaperski, S., Seelig, H., Schmidt, S., \& Fuchs, R. (2014). Regular aerobic exercise increases dispositional mindfulness in men: a randomized controlled trial. Mental Health and Physical Activity, 7, 111-119. https://doi.org/10.1016/j. mhpa.2014.02.003

Murphy, M., Mermelstein, L., Edwards, K., \& Gidycz, C. (2012). The benefits of dispositional mindfulness in physical health: a longitudinal study of female college students. Journal of American College Health, 60, 341-348. https://doi.org/10.1080/0 7448481.2011.629260

Puente-Díaz, R. (2012). The effect of achievement goals on enjoyment, effort, satisfaction and performance. International Journal of Psychology, 47, 102110. https://doi.org/10.1080/00207594.2011.585159

Roberts, K., \& Danoff-Burg, S. (2010). Mindfulness and health behaviors: Is paying attention good for you? Journal of American College Health, 59, 165173. https://doi.org/10.1080/07448481.2010.484452

Rogers, H., \& Morris, T. (2003). An overview of the development and validation of the Recreational Exercise Motivation Measure (REMM). In R. Stelter (Ed.), New approaches to exercise and sport psychology: Theories, methods and applications.
Proceedings of the 11th European Congress of Sport Psychology. CD-ROM (3 page full paper). Copenhagen: University of Copenhagen.

Rogers, H., Morris, T., \& Moore, M. (2008). A qualitative study of the achievement goals of recreational exercise participants. The Qualitative Report, 13, 706-734.

Roychowdhury, D. (2012). Examining reasons for participation in sport and exercise using the Physical Activity and Leisure Motivation Scale (PALMS). Doctoral dissertation, Victoria University, Melbourne, Australia.

Roychowdhury, D. (2018a). A comprehensive measure of participation motivation: Examining and validating the Physical Activity and Leisure Motivation Scale (PALMS). Journal of Human Sport \& Exercise, 13, 1-17. https://doi.org/10.14198/jhse.2018.131.20

Roychowdhury, D. (2018b). Functional significance of participation motivation on physical activity involvement. Psychological Thought, 11, 9-17. https://doi.org/10.5964/psyct.v11i1.255

Roychowdhury, D. (2019, July). Motivational approaches in promoting physical activity involvement. In Y. Kim (Chair), Holistic approaches to sport and physical activity participation in the Asian context (Symposium). 15th European Congress of Sport and Exercise Psychology, Munster, Germany. Roychowdhury, D. (2020). Using physical activity to enhance health outcomes across the life span. Journal of Functional Morphology and Kinesiology, 5, 1-13. https://doi.org/10.3390/jfmk5010002

Roychowdhury, D., \& Morris, T. (2013, July). Examining participation motivation in sport and exercise using discriminant function analyses. Paper presented at 13th International Society of Sport Psychology World Congress, Beijing, China.

Roychowdhury, D., \& Morris, T. (2019, July). The role of mindfulness in enhancing participation motivation in sport and exercise. In T. Morris (Chair), Motives for participation in sport and physical activity: New approaches (Symposium). 15th European Congress of Sport and Exercise Psychology, Munster, Germany.

Roychowdhury, D., Morris, T., \& Spittle, M. (2018, July). Mindfulness and participation motivation in sport and exercise. Paper presented at 8th AsianSouth Pacific Association of Sport Psychology International Congress, Daegu, South Korea.

Ryan, R., Frederick, C., Lepes, D., Rubio, N., \& Sheldon, K. (1997). Intrinsic motivation and exercise adherence. International Journal of Sport Psychology, 28, 335-354.

Silva, D., Naghavi, M., Duncan, B., Schmidt, M., de Souza, M., \& Malta, D. (2019). Physical inactivity as risk factor for mortality by diabetes mellitus in Brazil in 1990, 2006, and 2016. Diabetology \& Metabolic Syndrome, 11, 23. https://doi.org/10.1186/ s13098-019-0419-9 
Stanley, D., \& Cumming, J. (2010). Are we having fun yet? Testing the effects of imagery use on the affective and enjoyment responses to acute moderate exercise. Psychology of Sport and Exercise, 11, 582-590. https://doi.org/10.1016/j.psychsport. 2010.06.010

Stubbs, B., Koyanagi, A., Hallgren, M., Firth, J., Richards, J., Schuch, F., Rosenbaum, S., Mugisha, J., Veronese, N., Lahti, J., \& Vancampfort, D. (2017). Physical activity and anxiety: a perspective from the World Health Survey. Journal of Affective Disorders, 208, 545-552. https://doi.org/10.1016/j. jad.2016.10.028

Sutherland, G., \& Morris, T. (1997). Gender and participation motivation in 13-to 15-year-old adolescents. In R. Lidor \& M. Bar-Eli (Eds.), Proceedings of the IX World Congress of Sport Psychology (pp. 676-678). Netanya: ISSP.

Tapper, K., Shaw, C., Ilsley, J., Hill, A., Bond, F., \& Moore, L. (2009). Exploratory randomised controlled trial of a mindfulness-based weight loss intervention for women. Appetite, 52, 396-404. https://doi.org/10.1016/j.appet.2008.11.012

Teixeira, P., Carraça, E., Markland, D., Silva, M., \& Ryan, R. (2012). Exercise, physical activity, and self-determination theory: a systematic review. The International Journal of Behavioral Nutrition and Physical Activity, 9, article 78. https://doi.org/ 10.1186/1479-5868-9-78

Thomas, E., Muralidharan, A., Medoff, D., \& Drapalski, A. (2016). Self-efficacy as a mediator of the relationship between social support and recovery in serious mental illness. Psychiatric Rehabilitation Journal, 39, 352-360. https://doi.org/10.1037/ prj0000199

Ulmer, C., Stetson, B., \& Salmon, P. (2010). Mindfulness and acceptance are associated with exercise maintenance in YMCA exercisers. Behaviour Research and Therapy, 48, 805-809. https://doi. org/10.1016/j.brat.2010.04.009

Vallerand, R. (2008). On the psychology of passion: In search of what makes people's lives most worth living. Canadian Psychology, 49, 1-13. https://doi. org/10.1037/0708-5591.49.1.1

Vallerand, R. (2010). On passion for life activities: The dualistic model of passion. In M. P. Zanna (Ed.), Advances in experimental social psychology (pp. 97-193). San Diego, CA: Academic Press.

Vallerand, R. (2012). From motivation to passion: In search of the motivational processes involved in a meaningful life. Canadian Psychology, 53, 42-52. https://doi.org/10.1037/a0026377

Vallerand, R. (2015). The psychology of passion: a dualistic model. New York: Oxford University Press.

Vallerand, R., Blanchard, C., Mageau, G., Koestner, R., Ratelle, C., Léonard, M., Gagné, M., \& Marsolais, J. (2003). Les passions de l'âme: On obsessive and harmonious passion. Journal of Persona- lity and Social Psychology, 85, 756-767. https://doi. org/10.1037/0022-3514.85.4.756

Wang, J., Morris, T., Khoo, S., Hu, W., \& Tang, Y. (2013). Psychometric validation of the Physical Activity and Leisure Motivation Scale (PALMS) in a Chinese sample. Paper presented at International Society of Sport Psychology 13th World Congress, Beijing, China.

Wardoku, R., Blair, C., Demmer, R., \& Prizment, A. (2019). Association between physical inactivity and health-related quality of life in adults with coronary heart disease. Maturitas, 128, 36-42. https://doi.org/10.1016/j.maturitas.2019.07.005

Weinberg, R., Tenenbaum, G., McKenzie, A., Jackson, S., Anshel, M., Grove, R., \& Fogarty, G. (2000). Motivation for youth participation in sport and physical activity: Relationships to culture, selfreported activity levels, and gender. International Journal of Sport Psychology, 31, 321-346.

World Health Organization (2020a). Global health risks. Retrieved from https://www.who.int/healthinfo/global_burden_disease/GlobalHealthRisks_ report_part2.pdf [accessed June 19, 2020].

World Health Organization (2020b). Global recommendations on physical activity for health. Retrieved from https://www.who.int/dietphysicalactivity/publications/9789241599979/en/ [accessed June 19, 2020].

World Health Organization (2020c). More active people for a healthier world. Retrieved from https:// apps.who.int/iris/bitstream/handle/10665/272722/ 9789241514187-eng.pdf [accessed June 19, 2020].

Yoo, S., Han, M., Noh, Y., Kueh, Y., Khoo, S., \& Morris, T. (2018). Self-efficacy as an antecedent or mediator of motives for participation and amount of physical activity. Paper presented at 8th AsianSouth Pacific Association of Sport Psychology International Congress, Daegu, South Korea.

Zach, S., Bar-Eli, M., Morris, T., \& Rogers, H. (2012). Measuring motivation for physical activity: Validation of the Physical Activity and Leisure Motivation Scale. Athletic Insight, 4, 141-154.

Zarei, S., Memari, A, Moshayedi, P., Mosayebi, F., Mansournia, M., Khoo, S., \& Morris, T. (2016). Psychometric properties of Physical Activity and Leisure Motivation Scale in Farsi: an international collaborative project on motivation for physical activity and leisure. Archives of Iranian Medicine, 19, 704-711.

Zhou, L., Chlebosz, K., Tower, J., \& Morris, T. (2019). An exploratory study of motives for participation in extreme sports and physical activity. Journal of Leisure Research, 51, 56-76. https://doi.org/10.1080 /00222216.2019.1627175
Role of motives for participation in physical activity 